\title{
LABOUR ANALGESIA BY NEUROAXIAL BLOCKADE TECHNIQUE AND ITS LABOUR OUTCOME
}

KEY WORDS: Labour analgesia, epidural, maternal satisfaction.

\section{Dr. R.Shanthi \\ Malar *}

\section{Dr. V.Vijayalakshmi}

\section{Dr. P.Thenmozhi}

MD,DA, Dean, Govt. Stanley Medical College and Hospital, Chennai-13. *Corresponding Author

Assistant Professor,MS (O\&G),DNB (O\&G) Department of Obstetrics and Gynecology Govt. RSRM Lying in Hospital, Stanley Medical College, Chennai13.

MS (O\&G), Junior Resident,Department of Obstetrics and Gynecology Govt. RSRM Lying in Hospital, Stanley Medical College, Chennai-13.

BACKGROUND:Pain relief during labour is an important component of modern obstetric care and can be produced by neuraxial, systemic or inhalational analgesia. Recent meta-analyses have supported epidural analgesia as the most efficacious technique. A good labour analgesia should aim at good pain relief during delivery process, at the same time not causing foetal acidosis, ensures safe for both mother and the baby.

AIM OFTHE STUDY:To study the influence of epidural analgesia on maternal and neonatal outcome

MATERIALS AND METHODS:The study was conducted in the department of Obstetrics and Gynecology,GOVT.Stanley Medical College,Govt. RSRM LYING IN HOSPITAL,CHENNAI over a period of eight months from July 2019 to February 2021. The study was performed in 120 selected subjects. The study subjects were divided based on intervention-labour analgesia into 2 study groups.

In this study, change in vital parameters, fetal heart rate, assessment of pain score, Duration of first and second stage of labour, mode of delivery, APGAR score and the need for NICU admission were noted and recorded. Any complications during the course of labour were also recorded.

RESULTS: In this study, there was no significant difference in the mean duration of first and second stage of labour in both the study and control groups. The mean Apgar score of babies at one minute was 7.02 and at 5 minutes was 8.07 in the labour analgesia group and showed no significance. Maternal satisfaction for the effect of epidural analgesia, $60.00 \%$ of the patients of epidural analgesia, the incidence of satisfactory/very satisfactory experience was meaningfully and significantly more in labour analgesia group subjects compared to control group subjects by $30 \%$ with a 2 fold increase. CONCLUSION: As per this study labour analgesia using neuroaxial blockade technique are more likely to encounter increasing maternal satisfaction and good quality labour pain reduction.

\section{INTRODUCTION}

Labour is a complex mixture of biological mechanisms with mixed emotions and pain .People believed that this labour pain had lot of biological significance and an attempt to abolish it would be potentially dangerous to both mother and fetus and would alter uterine contractions and prolong the delivery. The pain of labour was the most severe thus making obstetrical analgesia highly in demand today.Numerous strategies either non-pharmacologic e.g., Hypnosis, Transcutaneous nerve stimulation, Acupuncture, Abdominal decompression, Yoga, parenteral drugs, Inhalational analgesics, Obstetric blocks or epidural blockade are considered to tackle this pain.Studies suggest that providing pain relief has positive impact on both mother and fetus and the outcome of labour. Out of all the analgesic methods tried ACOG suggests that "Epidural block is the most effective and least depressant (pharmacologic option) allowing for an alert mother.

The optimal analgesic is the one that can provide pain relief throughout the entire labour process with no side effects on both mother and fetus, should provide immediate onset of pain relief, effective pain relief, with minimal motor block, intact airway reflexes, mother should be awake and responsive, with very minimal maternal and neonatal depression and should have no depressant effects on the progress of the labour and the urge to bear down.

Newer advances include introduction of newer techniques like combined spinal epidurals, low dose epidurals facilitating ambulation, pharmacological advances like introduction of remifentanil for patient-controlled intravenous analgesia, introduction of newer local anaesthetics and adjuvants like ropivacaine, levo bupivacaine, sufentanil, clonidine and neostigmine, use of inhalational agents like sevoflurane for patient-controlled inhalational analgesia using special vaporizers, all have revolutionized the practice of pain management in labouring parturient.

\section{AIM OF THE STUDY:}

To study the influence of epidural analgesia on maternal and neonatal outcome

\section{METHODOLOGY}

The procedure was explained to the patient and an informed written consent was obtained. Once the patient gets into active labour with a per vaginal examination showing cervical dilatation of $3 \mathrm{~cm}$ or more, mother will be allocated to either of the two groups .Data will be collected for the intensity of pain, level of sensory blockade, intensity of motor blockade and possible side effects like nausea, vomiting, hypotension, head ache, urinary retention, fever,FHR abnormalities, every 5 minutes for 60 minutes following loading dose completion and every 30 minutes thereafter until delivery.

Partogram was marked to assess the progress of labour. The progress of labour is assessed with changes in cervical dilatation every 3 hours. The time interval between the administration of epidural drug to the full cervical dilatation will be noted. Incidence of the instrumental delivery and caesarean section will be recorded and analyzed and post partum complications if any will be noted. APGAR score of the neonate at $l$ and 5 minutes any NICU admissions also noted.

\section{$2^{\text {ND }}$ GROUP (NON EPIDURAL GROUP):}

Once the patient enters into the active phase of labour i.e., $\geq 3$ cms dilatation, with good uterine contractions, baseline pulse, blood pressure, fetal heart rate were recorded .Pulse 
rate, blood pressure, FHR were recorded every 30 minutes, pain score was noted according to visual analogue scale. Partogram was marked to assess the progress of labour.

\section{OUTCOME MEASURED}

1. Change in vital parameters, fetal heart rate.

2. Assessment of pain score according to visual analogue scale.

3. Duration of first stage of labour, duration of second stage of labour, mode of delivery were noted and recorded.

4. Condition of the baby was assessed by APGAR score at 1 minute and 5 minute interval after the delivery of the baby and the need for NICU admission.

5. Any complications during the course of labour were recorded. Patient was observed for 2 hours postpartum.

\section{RESULTS:}

Sixty patients were selected as per criteria and randomly allocated to the intervention groups.Mothers $(n=60)$ who desired labour analgesia during delivery were allocated in the first group (Labour Analgesia Group), whereas those $(n=60)$ who were not enthusiastic to labour analgesia during delivery were allocated in the second group (Control Group). In this study, an analytical approach was adopted to compare the effectiveness of delivery process with labour analgesia using neuroaxial blockade technique and its influence on the maternal and neonatal outcomes with delivery process without labour analgesia.

Data collected from 120 selected subjects were internally compared, tabulated, analysed and interpreted by using descriptive and inferential statistics based on the formulated objectives of the study.

\section{Table 1 : Gravida Status}

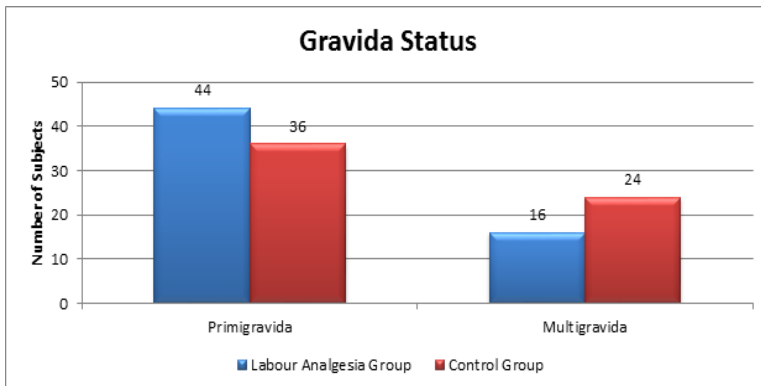

\begin{tabular}{|c|c|c|c|c|}
\hline Gravida Status & $\begin{array}{c}\text { Labour Analgesia } \\
\text { Group }\end{array}$ & $\%$ & $\begin{array}{c}\text { Control } \\
\text { Group }\end{array}$ & $\%$ \\
\hline Primigravida & 44 & 73.33 & 36 & 60.00 \\
\hline Multigravida & 16 & 26.67 & 24 & 40.00 \\
\hline Total & 60 & 100.00 & 60 & 100.00 \\
\hline
\end{tabular}

Table 2: gestational Age At Delivery

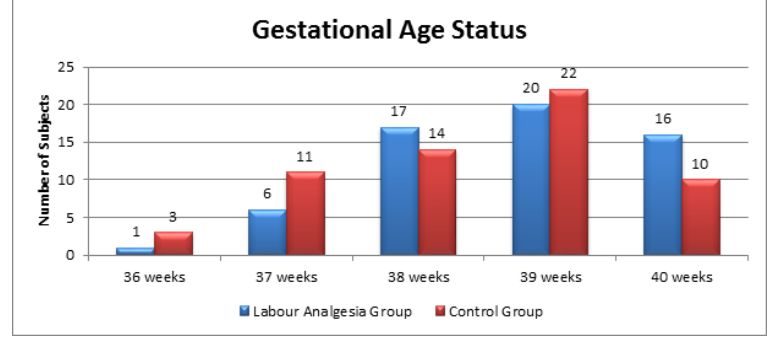

\begin{tabular}{|c|c|c|c|c|}
\hline $\begin{array}{c}\text { Gestational } \\
\text { Age Status }\end{array}$ & $\begin{array}{c}\text { Labour } \\
\text { Analgesia Group }\end{array}$ & $\%$ & Control Group & $\%$ \\
\hline 36 weeks & 1 & 1.67 & 3 & 5.00 \\
\hline 37 weeks & 6 & 10.00 & 11 & 18.33 \\
\hline 38 weeks & 17 & 28.33 & 14 & 23.33 \\
\hline 39 weeks & 20 & 33.33 & 22 & 36.67 \\
\hline 40 weeks & 16 & 26.67 & 10 & 16.67 \\
\hline Total & 60 & 100.00 & 60 & 100.00 \\
\hline
\end{tabular}

|www.worldwidejournals.com

\section{Table 3:hemodynamic Variables}

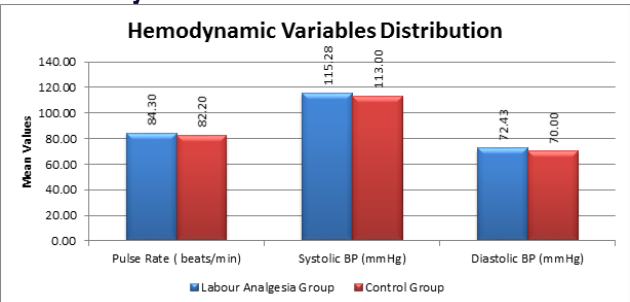

\begin{tabular}{|c|c|c|c|c|}
\hline & $\begin{array}{c}\text { Hemodynamic } \\
\text { Variables } \\
\text { Distribution }\end{array}$ & $\begin{array}{c}\text { Pulse } \\
\text { Rate } \\
\text { (beats/min) }\end{array}$ & $\begin{array}{c}\text { Systolic } \\
\text { BP } \\
(\mathrm{mmHg})\end{array}$ & $\begin{array}{c}\text { Diastolic } \\
\text { BP } \\
(\mathrm{mmHg})\end{array}$ \\
\hline $\begin{array}{c}\text { Labour } \\
\text { Analgesia } \\
\text { Group }\end{array}$ & Mean & 84.30 & 115.28 & 72.43 \\
\cline { 2 - 5 } & SD & 5.97 & 7.45 & 6.81 \\
\hline $\begin{array}{c}\text { Control } \\
\text { Group }\end{array}$ & Mean & 82.20 & 113.00 & 70.00 \\
\cline { 2 - 5 } & SD & 6.18 & 10.46 & 7.36 \\
\hline \multicolumn{2}{|c|}{$\begin{array}{l}\text { P value } \\
\text { Unpaired t Test }\end{array}$} & 0.061 & 0.171 & 0.063 \\
\hline
\end{tabular}

\section{Table 4:cervical Dilatation}

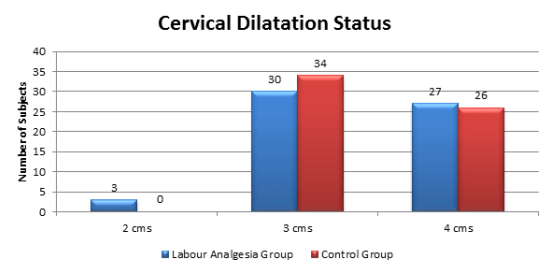

\begin{tabular}{|c|c|c|c|c|}
\hline Cervical Dilatation Status & $\begin{array}{c}\text { Labour } \\
\text { Analgesia } \\
\text { Group }\end{array}$ & $\%$ & $\begin{array}{c}\text { Control } \\
\text { Group }\end{array}$ & $\%$ \\
\hline $2 \mathrm{cms}$ & 3 & 5.00 & 0 & 0.00 \\
\hline $3 \mathrm{cms}$ & 30 & 50.00 & 34 & 56.67 \\
\hline $4 \mathrm{cms}$ & 27 & 45.00 & 26 & 43.33 \\
\hline Total & 60 & 100.00 & 60 & 100.00 \\
\hline $\begin{array}{c}\text { P value } \\
\text { Fishers Exact Test }\end{array}$ & \multicolumn{5}{|c|}{} \\
\hline
\end{tabular}

Table 5: duration Of Labour

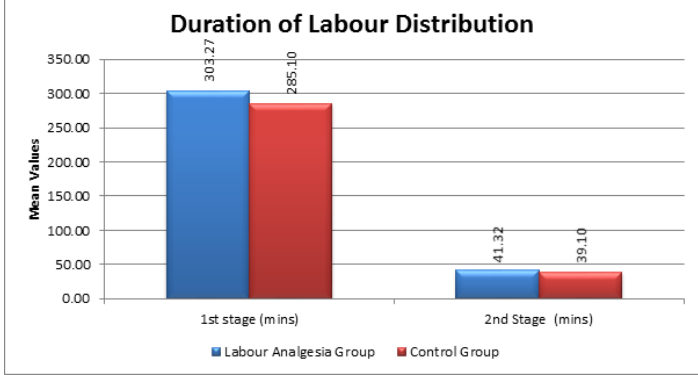

Table 6:mode Of Delivery

\begin{tabular}{|c|c|c|c|}
\hline \multicolumn{2}{|c|}{ Duration of Labour Distribution } & $\begin{array}{c}\text { 1st stage } \\
\text { (mins) }\end{array}$ & $\begin{array}{c}\text { 2nd Stage } \\
\text { (mins) }\end{array}$ \\
\hline Labour Analgesia Group & Mean & 303.27 & 41.32 \\
\cline { 2 - 4 } & SD & 84.38 & 10.06 \\
\hline Control Group & Mean & 285.10 & 39.10 \\
\cline { 2 - 4 } & SD & 55.33 & 6.59 \\
\hline \multicolumn{2}{|c|}{ P value Unpaired t Test } & 0.166 & 0.176 \\
\hline
\end{tabular}

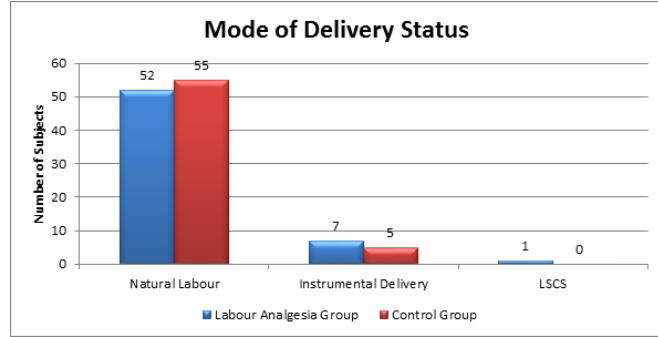




Table 7:mean Pain Score
\begin{tabular}{|c|c|c|c|c|}
\hline Mode of Delivery Status & $\begin{array}{c}\text { Labour } \\
\text { Analgesia } \\
\text { Group }\end{array}$ & $\%$ & $\begin{array}{c}\text { Control } \\
\text { Group }\end{array}$ & $\%$ \\
\hline Natural Labour & 52 & 86.67 & 55 & 91.67 \\
\hline Instrumental Delivery & 7 & 11.66 & 5 & 8.33 \\
\hline LSCS & 1 & 1.67 & 0 & 0.00 \\
\hline Total & 60 & 100.00 & 60 & 100.00 \\
\hline P value & \multicolumn{4}{|c|}{0.492} \\
\hline
\end{tabular}

\section{Table 10:intrapartum Complications}

\section{Intrapartum Complications Status}

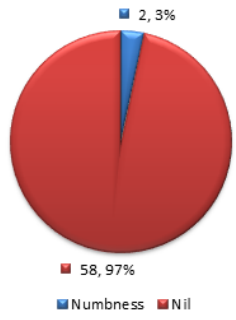

Table 11:postpartum Complications

Postpartum Complications Status

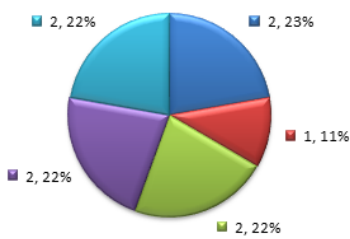

Backache $\square$ Headache $\square$ Numbness $\square$ Shivering uUrinary Retention

\section{CONCLUSION}

The labour analgesia group has significantly higher maternal satisfaction with delivery process when compared to control group. A two fold increase was observed. The labour analgesia group also had significantly lower pain score when compared to control group. A 55\% decrease was observed. This is due to good quality of pain relief in labour analgesia study group. The mean age distribution was not significantly different in both study groups. Hemodynamic variables were not significantly different between these two groups.There was no significant difference in the duration of labour between the study groups, even though labour analgesia group subjects had a longer duration of first and second stage of labour.In our study APGAR score at 1 minute and 5 minute showed no significant difference, showing better APGAR for babies born in labour analgesia group. The rate of cervical dilatation was not significantly different.The need for assisted vaginal delivery and LSCS was slightly higher in labour analgesia group. NICU admissions between two study groups showed no significant difference between study groups.Maternal complications (intrapartum and postpartum) were minimal and showed no significant difference between study groups.

As per this study labour analgesia using neuroaxial blockade technique are more likely to encounter

- Increasing maternal satisfaction

- Good quality labour pain reduction

- Patients receiving epidural analgesia have excellent and pleasurable birth experience.

- Neonatal outcome is satisfactory

- Minimal intra-partum and postpartum complications are found with labour analgesia.

\section{REFERENCES}

1. Dickinson JE, Paech MJ, McDonald SJ, Evans SF. Maternal satisfaction with childbirth and intrapartum analgesia in nulliparous labour. Aust N Z J Obstet Gynecol. 2003;43:463-8

2. Jackson A, Henry R, Avery N, et a!. Informed consent for labour epidurals: What labouring women want to know CanJ Anaesth 2000; 47:1068-73.

3. Chestnut DH, Weiner CP. Monitoring maternal heart rate during epidural injection of a test dose containing epinephrine (letter). Anesthesiology 1986; 64:839-40.

4. (a) Collins $1 C M$, Bevan DR, Beard RW.Fluid loading to reduce abnormalities of fetal heart rate and maternal hypotension during epidural analgesia in labour. Br Med 11978; 2:t460-I.(b) Ramanathan S. Masih A, Rock I, et al. Maternal and fetal effects of prophylactic hydration with crystalloids or colloids before epidural anesthesia. Anesth Analg 1983;62:673-8.

5. Zamora JE, Rosaeg OP, Lindsay MP, et al. 1-Iaemodynamic consequences and uterine contractions following 0.5 or 1.0 litre crystalloid infusion before www.worldwidejournals.com $\mid$ 


\section{obstetric epiduralanalgesia.CanJAnaesth 1996}

6. Kinsella SM, Pirlet M, Mills MS, et al. Randomized study of intravenous fluid preload before epidural analgesia during labour. Br JAnaesth 2000;85:31 1-3.

7. Ellington C, Katz VL, Watson WJ, et al. The effect of lateral tilt on maternal andfetal hemodynamnic variables. Obstet Gynecol 1991; $77: 201-3$.

8. Meister et al; A Comparison of Epidural Analgesia with $0.125 \%$ Ropivacaine with Fentanyl Versus $0.125 \%$ Bupivacaine with Fentanyl during Labor. AJA 2002;(18):267-27 1.

9. M. Dresner Ropivacaine $0.2 \%$ versus bupivacaine $0.1 \%$ with fentanyl: a double blind comparison for analgesia during labour ; Br J Anaesth 2000; 85: 826-9.

10. Lottan M, Mashiach R, Namestnikov M. Hematologic diseases. In: Birnbach DJ, Gatt SP, Datta S, editors. Textbook of Obstetric Anesthesia,New York: Churchill Livingstone;2000:586-596 